\title{
The Influence of Nutritional Awareness Program on Knowledge and Behavior of Egyptian Medical Students regarding Junk Food
}

\author{
Heba R. Elareed and Shaimaa A. Senosy \\ Community Medicine, Faculty of Medicine, Beni-Suef University, Egypt
}

Received : May, 2018 Accepted: August, 2018

\begin{abstract}
Background: It is the $21^{\text {st }}$ century and junk food has gone global. Far worse, junk food is now available everywhere all over the world. Objective: to measure the effect of a nutrition education program on medical students' knowledge and behavior and to evaluate their knowledge and behavior regarding junk food. Method: A total of 184 medical students from Beni- Suef University were enrolled in this non controlled intervention study. A selfadministered questionnaire was used to assess the students' knowledge and behavior about junk food, before and after being subjected to a nutrition educational program. Results: Of the 184 medical students, $(36.4 \%)$ were males while $(63.6 \%)$ were females. The mean age of students was $(20.45 \pm 1.24)$ years (range 18-23 years). The nutrition awareness program resulted in statistically significant improvement $(\mathrm{p}<0.001)$ in students' knowledge and behavior. $87.5 \%$ and $55.4 \%$ of medical students were aware of the definition and the composition of the junk food respectively. Time constraints and the availability of junk food were the main cause to choose junk food among students with suboptimal behavior (29.5\% and $23.3 \%$ respectively). Conclusion: the interventional awareness program showed a positive influence on improving the knowledge and behavior of medical students of Beni- Suef University regards junk food.
\end{abstract}

Keywords: Junk food; knowledge; food composition; obesity; medical students

Corresponding auther: Heba R. Elareed, E-mails: dr_heba_alareed@yahoo.com

\section{Introduction}

Junk food is a quick, unhealthy food, which is easy to be made and to be consumed. It lacks the nutritional value and is a caloric density food. Junk food is rich in refined sugar, white flour, polyunsaturated fats, salts and numerous food additives, but low in protein, vitamins and fibers. ${ }^{1}$

Junk food cause strokes, high blood pressure, type II diabetes mellitus, heart attacks raised LDL cholesterol levels and cancer colon. It also leads to weight gain and obesity. ${ }^{2}$

University life creates a different environment for students, there is no time for meal preparation, planning, and eating. Students may have the feeling of parent's independence, with preference for eating away whenever they want. ${ }^{3}$ Youth is consuming junk food meals heavily more than older people. ${ }^{4,5}$ Taste, time constrains and costs, consider the main predisposing factors that make medical students consume junk food. ${ }^{6}$

Several studies have found adolescents staying away from home are associated with increased consumption of junk food with high calorie intake.

Currently, Junk food consumption has increased all over the world ${ }^{8,9}$ so, to limit consumption of junk food, we should pay attention to the interventions directed to youth. $^{10}$

Only a few nutrition education programs are designed for university students contrary to others directed to children 
and elderly. ${ }^{11}$ Therefore it is mandatory to design interventions to improve future doctor's dietary knowledge and behavior.

The aim of the current study was to explore the influence of a nutrition education program on medical students' knowledge and behavior regarding junk food and to evaluate their knowledge and behavior regarding junk food.

\section{Methods}

This non-controlled interventional study was carried out in the faculty of Medicine, Beni-Suef University, Northern Upper Egypt, during the academic year 2017-2018.

A convenient sample of 184 medical students who were present in their sessions and lectures from October 2017 to March 2018, was participating in the study. The sample size was estimated using Epi-Info version 7 Stat Calc, [Center for Disease Control (CDC), WHO], depending on the following criteria; confidence level of $95 \%$, a margin of error of $5 \%$, improvement rate of $50 \%$ and non-response rate of $25 \%$. The sample was doubled but 37 students were excluded as they were lost to follow up.

The study was conducted through 3 phases; During the first phase, baseline data were obtained from the participants during their sessions and lectures in October 2017 using a semi-structured self-administrated questionnaire designed in 4 parts, the first showed sociodemographic characteristics of studied subjects (age, sex, residence, and parents' educational level), the second assessed students' knowledge about 5 aspects (meaning of junk food, junk food composition, composition of soft drinks, awareness about hazards of junk food and awareness about relation between obesity and junk food), the third evaluated their behavior in 6 aspects (frequency of consumption of junk food, replacing main meal with junk food, size portion of junk meal, beverage consumption with junk food, evaluation of ingredient list, and evaluation of caloric content) and the forth explored the factors provoked them to consume junk food.

Before using the questionnaire for data collection, a pilot study on 20 students was carried out to test the reliability and validity of the questionnaire. The Cronbach's alpha for reliability was 0.78 while content validity was assessed by a professor of public health.

For assessment of knowledge questions, each correct answer was given one mark, while the wrong answer was evaluated as zero; the score ranged from 0 to 5 marks and was classified as 0-3 for suboptimal knowledge, and 4-5 scored as optimal knowledge. Regarding the scoring of behavior questions, the two marks were given for good behavior; one mark for average and zero for bad ones, the score ranged from 0 to 12 points, so the behavior was classified into suboptimal behavior for the score "0-6", and optimal behavior for "7-12"

The second phase, a nutrition awareness program was constructed by researchers to raise students' knowledge and try to modify their behaviors. The program was applied in 3 sessions; each lasted for 30 minutes. Arabic-language slide presentations with figures and graphs, supplemented by printing handouts as take-home notes, aimed at providing basic information on junk food definition, composition, the importance of seeing the calories and a list of ingredients on the label of consumed food, hazards especially risk of obesity, factors provoking the students to consume junk food, and how to overcome these factors.

The third phase was 3 months later, all students were assessed again over their knowledge and behavior using the same questionnaire and the scoring system was similar to that of the baseline assessment. A comparison between pre and post intervention program was done to find 
out the degree of change in knowledge and behavior.

Data analysis: The accuracy of data entry was assured by a double-entry method from the case report forms to the database. Data were analyzed using the software, Statistical Package for Social Science (SPSS Inc. Released 2009, PASW Statistics for Windows, version 18.0: SPSS Inc., Chicago, Illinois, USA), then processed and tabulated. Normal data distribution was confirmed by the Kolmogorov-Smirnov test. Calculation of percentage for Frequency distribution and mean and standard deviation for descriptive statistics were done. The appropriate test of significance was applied. Chi-square test was also applied and Alpha error was set at a 5\% level to assess the relations. $\mathrm{P}$ values of less than 0.05 were considered significant. Paired t test was used for normally distributed data to compare pre and post data.

\section{Ethical considerations:}

This study was approved by the Ethical Committee of the Faculty of Medicine, Beni-Suef University. All students participated voluntarily; Privacy and confidentiality of data were assured all through the research work. Informed consent was taken from students.

\section{Results}

Of the total of 184 medical students, who have completed the three phases of this interventional study, 67 (36.4\%) were males while $117(63.6 \%)$ were females. The age of students ranged between 18$23(20.45 \pm 1.24)$ years. $98(53.3 \%)$ of students were rural residents and 86 $(46.7 \%)$ were from the urban area. Furthermore, $84(45.7 \%)$ of their fathers and $45(24.5 \%)$ of their mothers had a university or higher education (table 1)

Of the 184 students who were participating in the program, 24 (13\%) were found to have good knowledge about junk food (Figure 1). The results also showed that there were no statistically significant differences between students with optimal knowledge and those with suboptimal knowledge regarding the age of students, their sex, and education of their father and mother $(p>0.05)$, while there was statistically significant differences regarding the residence of students $(\mathrm{p}<0.05)$ (Table 1).

Only the residence showed statistically significant differences between students with optimal behavior and those with suboptimal behavior $(\mathrm{p}<0.05)$ (Table 2)

Medical students, who knew the definition and were aware of the composition of the junk food, were $(87.5 \%)$ and $(55.4 \%)$ respectively. Most of the participant $(92.4 \%)$ didn't know that artificially added phosphate, as a preservative, is always included in soft drinks. less than one third $(26.1 \%)$ were oriented about the hazards of junk food on health, nearly half students $(48.4 \%)$ were aware about the relation between junk food and obesity (Table 3).

After the nutritional awareness program, the rates of optimal knowledge about the meaning, composition of junk food, composition of soft drinks, hazards of junk food and relation with obesity, improved significantly from $87.5 \%$, $55.4 \%, 7.6 \%, 26.1 \%$ and $48.4 \%$ to a high of $94.6 \%, 67.9 \%, 44 \%, 69.9 \%$ and $78.8 \%$ respectively $(\mathrm{p}<0.001)$ (Table 3$)$.

Regarding the provoking factors among students with suboptimal behavior (176 students), time constraints and the availability of junk food were the most prominent causes $(29.5 \%$ and $23.3 \%$ respectively), followed by peer pressure (18.8\%). (Table 4)

The optimal knowledge and optimal behavior of participants regarding junk food improved significantly from $13 \%$ and $4.3 \%$ to a high of $53.3 \%$ and $16.8 \%$ respectively $(\mathrm{p}<0.001)$ (figure 2$)$.

\section{Discussion}

Junk food has become a prominent feature of the diet of university students, 
Table 1: Association between socio-demographic characteristics of medical students and their knowledge about junk food, Beni-Suef, 2018

\begin{tabular}{|c|c|c|c|c|c|}
\hline \multicolumn{2}{|c|}{$\begin{array}{l}\text { Socio-demographic } \\
\text { characteristics }\end{array}$} & $\begin{array}{l}\text { Suboptimal } \\
\text { Knowledge } \\
n=160(\%)\end{array}$ & $\begin{array}{c}\text { Optimal } \\
\text { Knowledge } \\
\text { n=24 }(\%)\end{array}$ & $\begin{array}{c}\text { Total } \\
\text { Knowledge } \\
\text { n=184 }(\%)\end{array}$ & $P$ value \\
\hline \multicolumn{2}{|c|}{ Age (Mean \pm SD) years } & $20.5 \pm 1.2$ & $19.8 \pm 1.19$ & $20.45 \pm 1.24$ & 0.178 \\
\hline \multirow[t]{2}{*}{ Sex } & Male & $59(36.9)$ & $8(33.3)$ & $67(36.4)$ & \multirow{2}{*}{0.463} \\
\hline & Female & $101(63.1)$ & $16(66.7)$ & $117(63.6)$ & \\
\hline \multirow{2}{*}{$\begin{array}{l}\text { Father } \\
\text { education }\end{array}$} & Secondary or less & $88(55)$ & $12(50)$ & $100(54.3)$ & \multirow{2}{*}{0.404} \\
\hline & University or higher & $72(45)$ & $12(50)$ & $84(45.7)$ & \\
\hline \multirow{2}{*}{$\begin{array}{l}\text { Mother } \\
\text { education }\end{array}$} & Secondary or less & $123(76.9)$ & $16(66.7)$ & $139(75.5)$ & \multirow{2}{*}{0.20} \\
\hline & University or higher & $37(23.1)$ & $8(33.3)$ & $45(24.5)$ & \\
\hline \multirow[t]{2}{*}{ Residence } & Urban & $80(50)$ & $6(25)$ & $86(46.7)$ & \multirow{2}{*}{$0.018^{*}$} \\
\hline & Rural & $80(50)$ & $18(75)$ & $98(53.3)$ & \\
\hline
\end{tabular}

*p value is considered significant

Table 2: Association between socio-demographic characteristics of medical students and their behavior regarding junk food, Beni-Suef, 2018

\begin{tabular}{|c|c|c|c|c|c|}
\hline \multicolumn{2}{|c|}{$\begin{array}{c}\text { Socio-demographic } \\
\text { characteristics }\end{array}$} & $\begin{array}{c}\text { Suboptimal } \\
\text { Behavior } \\
n=176(\%)\end{array}$ & $\begin{array}{c}\text { Optimal } \\
\text { Behavior } \\
n=8(\%)\end{array}$ & $\begin{array}{c}\text { Total } \\
\text { Behavior } \\
\text { n=184 }(\%)\end{array}$ & $P$ value \\
\hline \multicolumn{2}{|c|}{ Age (Mean \pm SD) years } & $20.4 \pm 1.2$ & $21.25 \pm 1.28$ & $20.45 \pm 1.24$ & 0.912 \\
\hline \multirow[t]{2}{*}{ Sex } & Male & $65(36.9)$ & $2(25)$ & $67(36.4)$ & \multirow{2}{*}{0.391} \\
\hline & Female & $111(63.1)$ & $6(75)$ & $117(63.6)$ & \\
\hline \multirow{2}{*}{$\begin{array}{l}\text { Father } \\
\text { education }\end{array}$} & Secondary or less & $96(54.5)$ & $4(50)$ & $100(54.3)$ & \multirow{2}{*}{0.54} \\
\hline & University or higher & $80(45.5)$ & $4(50)$ & $84(45.7)$ & \\
\hline \multirow{2}{*}{$\begin{array}{l}\text { Mother } \\
\text { education }\end{array}$} & Secondary or less & $132(75)$ & $7(87.5)$ & $139(75.5)$ & \multirow{2}{*}{0.37} \\
\hline & University or higher & $44(25)$ & $1(12.5)$ & $45(24.5)$ & \\
\hline \multirow[t]{2}{*}{ Residence } & Urban & $79(44.9)$ & $7(87.5)$ & $86(46.7)$ & \multirow{2}{*}{$0.021 *$} \\
\hline & Rural & $97(55.1)$ & $1(12.5)$ & $98(53.3)$ & \\
\hline
\end{tabular}

*p value is considered significant 
Table 3: Improvement of the participating students' knowledge about junk food in after the nutritional awareness program, Beni-Suef, 2018

\begin{tabular}{|c|c|c|c|c|}
\hline Items & Scoring & Before & After & $P$ value \\
\hline \multirow{2}{*}{ Definition of junk food } & $\begin{array}{l}\text { Optimal } \\
\text { Knowledge }\end{array}$ & $161(87.5)$ & $174(94.6)$ & \multirow[t]{2}{*}{$<0.001^{*}$} \\
\hline & $\begin{array}{l}\text { Suboptimal } \\
\text { Knowledge }\end{array}$ & $23(12.5)$ & $10(5.4)$ & \\
\hline \multirow{2}{*}{ Composition of junk food } & $\begin{array}{l}\text { Optimal } \\
\text { Knowledge }\end{array}$ & $102(55.4)$ & $125(67.9)$ & \multirow[t]{2}{*}{$<0.001^{*}$} \\
\hline & $\begin{array}{l}\text { Suboptimal } \\
\text { Knowledge }\end{array}$ & $82(44.6)$ & $59(32.1)$ & \\
\hline \multirow{2}{*}{ Composition of Soft drinks } & $\begin{array}{l}\text { Optimal } \\
\text { Knowledge }\end{array}$ & $14(7.6)$ & $81(44)$ & \multirow[t]{2}{*}{$<0.001^{*}$} \\
\hline & $\begin{array}{l}\text { Suboptimal } \\
\text { Knowledge }\end{array}$ & $170(92.4)$ & $103(56)$ & \\
\hline \multirow{2}{*}{ Hazard of junk food } & $\begin{array}{l}\text { Optimal } \\
\text { Knowledge }\end{array}$ & $48(26.1)$ & $128(69.9)$ & \multirow[t]{2}{*}{$<0.001^{*}$} \\
\hline & $\begin{array}{l}\text { Suboptimal } \\
\text { Knowledge }\end{array}$ & $136(73.9)$ & $56(30.4)$ & \\
\hline \multirow{2}{*}{$\begin{array}{l}\text { Relation between junk food and } \\
\text { Obesity }\end{array}$} & $\begin{array}{l}\text { Optimal } \\
\text { Knowledge }\end{array}$ & $89(48.4)$ & $145(78.8)$ & \multirow[t]{2}{*}{$<0.001^{*}$} \\
\hline & $\begin{array}{l}\text { Suboptimal } \\
\text { Knowledge }\end{array}$ & 95 (51.6) & 39 (21.2) & \\
\hline \multirow[b]{2}{*}{ Overall } & $\begin{array}{l}\text { Optimal } \\
\text { Knowledge }\end{array}$ & $24(13)$ & $98(53.3)$ & \multirow[t]{2}{*}{$<0.001^{*}$} \\
\hline & $\begin{array}{l}\text { Suboptimal } \\
\text { Knowledge }\end{array}$ & $160(87)$ & 86 (46.7) & \\
\hline
\end{tabular}

*p value is considered significant

Table 4: Factors provoked medical students with suboptimal behavior regarding junk food, Beni-Suef, 2018

\begin{tabular}{|l|r|}
\hline \multicolumn{1}{|c|}{ Factors } & \multicolumn{2}{|c|}{$\begin{array}{c}\text { Suboptimal behavior } \\
\text { n=176 (\%) }\end{array}$} \\
\hline Time & $52(29.5)$ \\
\hline Availability & $41(23.3)$ \\
\hline Peer & $33(18.8)$ \\
\hline Taste And Quality & $25(14.2)$ \\
\hline Service And Delivery & $11(6.2)$ \\
\hline Price & $10(5.7)$ \\
\hline Brand and variety & $4(2.3)$ \\
\hline
\end{tabular}

especially in the developing country. This study described the knowledge and behavior of medical students towards junk food and its impact on health and to assess the impact of nutrition education program on their knowledge and behavior.
The current study showed that there is a statistically significant improvement in knowledge and behavior after the intervention program. These findings were in agreement with a study conducted by Vardanjani et al. among girl students at primary schools in Shahr- 
e-kord city, which illustrated a significant improvement in the knowledge, attitude and performance of pupils regarding junk food intake after intervention. ${ }^{12}$ So it is mandatory to conduct intervention programs for university student to improve their knowledge and behavior regarding junk food consumption.

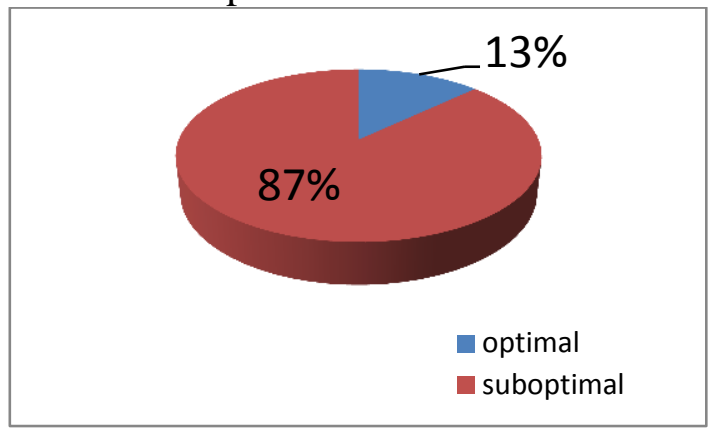

Figure 1: Knowledge of medical students about junk food, Beni-Suef, 2018

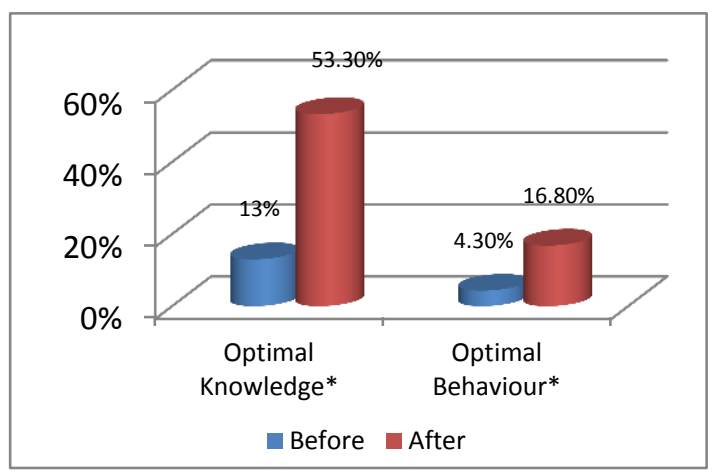

* $p$ value is considered significant

Figure 2: Assessment of students' optimal knowledge and behaviour about junk before and after the nutritional awareness program, Beni-Suef, 2018

The study illustrated that $92.4 \%$ of students didn't know that artificially added phosphate, as a preservative, is always included in soft drinks. These also were similar to what was reported in a study conducted among 300 medical Chennai students that showed that $67 \%$ of medical students were not aware that artificially added phosphate is added in carbonated soft drinks ${ }^{13}$, phosphate containing soft drinks harmfully affects the different body system; as renal calculi are more prevalent in individuals consuming phosphate containing soft drinks. So it is mandatory to increase the awareness of soft drinks harmful effect on health. While the participants showed their optimal knowledge about the definition and the composition of the junk food $(87.5 \%, 55.4 \%$, respectively) similar to Chennai study results. ${ }^{13}$ The majority of adolescents $73.9 \%$ having suboptimal knowledge regarding harmful effects of Junk food, similar to a study conducted in India where most of adolescents $81.67 \%$ (49) having below average knowledge regarding harmful effects of Junk food. ${ }^{14}$

The study also showed that more than half of the students $(51.6 \%)$ didn't know the relation between consumption of junk food and obesity similar to a study in Bangladesh conducted among university students. ${ }^{15}$

Demand for junk food depends heavily on the ease of consumer access to the product. The junk food producer has continually found ways to make its product more accessible, the study showed that $23.3 \%$ of participant's choice of junk food was based on the availability and $29.5 \%$ elect because of the time constraints and time of operation and $18.8 \%$ of the young medicos choose the junk food restaurants because of Peer pressure while $14.2 \%$ choose it because of the taste. In contrary to the Saudi study, which illustrated that the cause of eating junk food is for its' delicious taste, followed by convenience. ${ }^{13}$ and also contrary to an Indian study, which explained that young Indian consumer have the greatest value for taste and quality followed by ambience and hygiene. $^{16}$

Regarding residence, there is a statistically significant difference between urban and rural students with respect to their mean knowledge regarding junk food consumption, Similar to a study conducted in India in 2015 agreed with this study in statistical a significant difference of knowledge regarding junk food consumption 
between Urban and Rural area school children. ${ }^{17}$

Also, there was a statistically significant difference between residence and their behavior, as $87.5 \%$ of the study sample of baseline optimal behavior were urban students, this agreed to a study conducted in Cameroon, Africa. ${ }^{18}$

University Students' parents should pay attention to their eating styles and behavior in order not to disseminate this behavior to all family members. Students should be encouraged to see the ingredients and calories on packaging, to differentiate between nutrient density and energy dense foods, and to have some important terms such as "only 10\% fat", "low in sugar" on food labels.

Youth should lead healthy, responsible and sustainable lifestyle habits. School and university-wide messages must be disseminated throughout the curriculum. ${ }^{19}$

\section{Conclusion}

The study showed that there is an improvement of medical students' knowledge and behavior after the Interventional program and highlighted that medical students, partly know the hazards of sustained consumption of high sodium, trans-fatty acids rich junk food and artificially added phosphate rich soft carbonated drinks. And revealed that there is a difference between the awareness of a nutritious diet and the practice of its' consuming. But being one of the developing countries, our students are in need of effective targeted educational and awareness programs.

It is optimal to design an awareness program regarding the impact of consumption of junk food among the schools and colleges.

Limitations of the study: The selection of a convenient sample of students who took the questionnaire sheets to fill and return them back to the investigators rendering it a less representative sample.
So, the random stratified sampling method is better for study design.

The sample population does not fully represent all university students across Egypt because the study participants were drawn from one university.

\section{Acknowledgement}

First and foremost, thanks to ALLAH to whom we relate the success in achieving this work. And I want to thank medical students who accepted to participate in the current study and thank my family who supported me.

Conflict of interest: none

\section{References}

1. Pizza G and Rather KI (2012) beyond fast food and slow motion: weighty contributors to obesity epidemic. J Endocrinal Invest; 35(2), 236-242.

2. Zhu SP, Ding YJ, Lu XF, Wang HW, Yang M, Wang JX (2008) Study on factors related to top 10 junk food consumption at 8 to 16 years of age. Haidian District of Beijing Zhonghua Liu Xing Bing XueZaZhi; 29(8), 757-762.

3. Stockton S and Baker D (2013) College students' perceptions of fast food restaurant menu items on health. American Journal of Health Education; 44(2), 74-80.

4. Nielsen SJ, Siega-Riz AM, Popkin BM (2002) Trends in food locations and sources among adolescents and young adults. Prev Med; 35:107-113.

5. Paeratakul S, Ferdinand DP, Champagne CM, Ryan DH \& Bray GA (2003) Fast-food consumption among US adults and children: dietary and nutrient intake profile. J Am Diet Assoc; 103, 1332-1338.

6. Driskell JA, Kim YN, Goebel KJ (2005) Few differences found in the typical eating and physical activity habits of lower-level and upper-level university students. J Am Diet Assoc; 105, 798801.

7. Larson NL, Neumark-Sztainer DR, Laska MN, Story MT (2011) Young 
Adults and Eating Away from Home: Associations with Dietary Intake Patterns and Weight Status Differ by Choice of Restaurant. J Am Diet Assoc; 111(11), 1696-1703.

8. Bahadoran Z, Mirmiran P, Golzarand M, Hosseini-Esfahani F, Azizi F (2012) Fast food consumption in Iranian adults; dietary intake and cardiovascular risk factors: Tehran Lipid and Glucose Study. Arch Iran Med;15(6), 346-351.

9. Sharifirad G, Yarmohammadi P, Azadbakht L, Morowatisharifabad MA, Hassanzadeh A (2013) Determinants of Fast Food Consumption among Iranian High School Students Based on Planned Behavior Theory. J obes; 3)2), 269-265. 10. Larson NI, Neumark-Sztainer DR, Story MT, Wall MM, Harnack LJ, Eisenberg ME (2008) Fast food intake: longitudinal trends during the transition to young adulthood and correlates of intake. J Adolesc Health;43(1), 79-86.

11. Lua PL and Wan Putri Elena WD (2012) The impact of nutrition education interventions on the dietary habits of college students in developed nations: a brief review, Malays J Med Sci: vol. 19, no. 1, 4-14.

12. Vardanjani AE, Reisi M, Javadzade H, Pour ZG, Tavassoli E (2004) The Effect of nutrition education on knowledge, attitude, and performance about junk food consumption among students of female primary schools, J Educ Health Promot; 6, 4-53.

13. Thamarai R, Sivakumar K, Kalavathy P (2015) Awareness of health cosequences of junk food among medical students, International Journal of Recent Scientific Research.2015 March; Vol. 6, Issue, 3, 3203-3207.

14. Vandana Sharma MS (2013) Adolescents Knowledge Regarding Harmful Effects of Junk food, Journal of Nursing and Health Science Volume 1, Issue 6. www.iosrjournals.org

15. Karmakar P, Jahan N, Banik S, Das A, Rahman KA, et al. (2016) Food Habits, Obesity and Nutritional Knowledge among the University Students in Noakhali Region of Bangladesh: A Cross Sectional Study. J Food Nutr Disor 5:4. doi:10.4172/23249323.1000201.

16. Goyal N and Singh NP (2007) Consumer perception about fast food in India: an exploratory study. British Food Journal;109, 182 - 195.

17. Lavanya uriti and A Padmaja (2015) A Comparative Study to Assess the Knowledge Regarding Effects of Junk Food Consumption between Urban and Rural Areas, School Children at Tirupati, India. Biohouse. Journal of Advanced Medical Research; 1(3).

18. Dapi LN, Nouedoui C, Janlert U, $\mathrm{Ha}^{\circ}$ glin L (2005) Adolescents' food habits and nutritional status in urban and rural areas in Cameroon, Africa. Scandinavian Journal of Nutrition; 49 (4): $151 / 158$.

19. Higgs J and Styles K (2006) Principles and practical aspects of healthful school vending. British Nutrition Foundation Nutrition Bulletin; 31, 225-232. 